\title{
Metabolic rate, genetic and microclimate variation among springtail populations from sub-Antarctic Marion Island
}

\author{
Angela McGaughran • Peter Convey • \\ Mark I. Stevens $\cdot$ Steven L. Chown
}

Received: 29 August 2009 / Revised: 23 December 2009 / Accepted: 17 January 2010 / Published online: 9 February 2010

(C) Springer-Verlag 2010

\begin{abstract}
Measurement of metabolic rates (made at $10^{\circ} \mathrm{C}$ ) of individuals of the springtail Cryptopygus antarcticus tra$v e i$ from six geographically distinct populations on subAntarctic Marion Island were combined with mitochondrial DNA (COI) haplotype analysis to examine in parallel both physiological and genetic variation of distinct populations. We found evidence of genetic differentiation among populations and a general indication of long-term isolation with limited gene flow. While we found support for an overall pattern of metabolic rate structure among populations from different geographic locations on the island (mean rate $=0.0009-0.0029 \mu \mathrm{O} \mathrm{O}_{2} \mu \mathrm{g}^{-1} \mathrm{~h}^{-1}$ for populations of a mean individual mass of $8-26 \mu \mathrm{g}$ ), we were unable to
\end{abstract}

Electronic supplementary material The online version of this article (doi:10.1007/s00300-010-0767-2) contains supplementary material, which is available to authorized users.

A. McGaughran ( $($ )

Allan Wilson Centre for Molecular Ecology and Evolution,

Massey University, Private Bag 11-222,

Palmerston North, New Zealand

e-mail: ang.mcgaughran@gmail.com

P. Convey

British Antarctic Survey, Natural Environment Research Council,

High Cross, Madingley Rd, Cambridge CB3 OET, UK

M. I. Stevens

South Australian Museum, PO Box 5000, Adelaide, Australia

M. I. Stevens

School of Biological Sciences, Flinders University,

PO Box 5001, Adelaide, Australia

S. L. Chown

Department of Botany and Zoology,

Centre for Invasion Biology, Stellenbosch University,

Private Bag X1, Matieland 7602, South Africa demonstrate a coherent common pattern between this and genetic variation. However, spatial structure in metabolic rate variation was strongly related to the extent of variability in microclimate among sites, and also showed some indication of a phylogeographic signal. Thus, over the relatively short timescale of Marion Island's history ( $<1$ million years), the periodic geographic barriers that have driven population differentiation from a molecular perspective may also have resulted in some physiological differentiation of populations.

Keywords Antarctica $\cdot$ Metabolic rate $\cdot$ Genetics . Microclimate $\cdot$ Springtail $\cdot$ Variability

\section{Introduction}

Spatial variation in the environment is known to affect species in various ways, and subsequently to elicit a variety of responses. In particular, differences in energy assimilation and expenditure are important in shaping population structure and dynamics (e.g. Convey 1998; Kozłowski et al. 2004; Lardies et al. 2004). In polar environments, physiological processes that influence energy assimilation and use, and their variation in response to environmental conditions, are likely to have a significant influence on the evolution of life history strategies (Convey 1996a; Clarke 1998; Chown and Convey 2007), especially since diversity is low and extreme conditions are either common or unpredictable (Peck et al. 2006). Indeed, adaptive strategies of Antarctic terrestrial taxa are largely dominated by responses of individuals to their immediate environment, and include characteristics which maximise activity, growth, development and survival (Convey 1996a, b; Sinclair et al. 2003). Under such circumstances, physiological variation among individuals 
and populations that generates differences in fitness may be significant.

Such differences have received limited attention in an ecological context in the region (e.g. Davey and Rothery 1996; Convey 1998; Klok and Chown 2003, 2005). Investigation of intraspecific variation in metabolic energy supply in particular would prove beneficial in this context because metabolic rate (generally measured indirectly as $V \mathrm{O}_{2}$ ) is essentially a measure of the energetic cost of living, its function being to provide the ATP that fuels all processes within the organism (Clarke 1993, 1998). Thus, metabolic efficiency likely has a significant influence on organism fitness (Kozłowski et al. 2004; Lardies et al. 2004; Lardies and Bozinovic 2008).

Several studies from the polar regions have shown that metabolic rates differ between populations or species from habitats differing in latitude, altitude and (correspondingly) temperature (e.g. Block and Young 1978; Strømme et al. 1986; Sømme et al. 1989; Chown 1997). In some cases, such differences have been attributed to metabolic cold adaptation (MCA), a phenomenon, where at the same trial temperature, species from colder locations have elevated metabolism compared with those from warm locations (see Block 1990). However, differential fitness among populations may also be driven by processes operating at the molecular scale. Several studies have demonstrated a genetic contribution to variation in individual energy budgets, and heterozygosity is often spatially or temporally correlated with variation in environmental factors and whole-animal physiological processes (e.g. Mitton et al. 1986; Teska et al. 1990; Pujolar et al. 2005). Individuals with greater heterozygosity have also been shown to have a greater aerobic scope for activity (Mitton et al. 1986). Thus, a variety of factors may influence contemporary patterns of population metabolic rate structure.

Recently, evidence of regionalisation and molecular divergence within terrestrial arthropod species has been identified across sub-Antarctic Marion Island (Mortimer and Jansen van Vuuren 2006; Myburgh et al. 2007). Such patterns are generally true for springtails in polar regions due in part to the perceived constraints on long-distance dispersal opportunities (e.g. Hawes et al. 2008a; McGaughran et al. 2009). Evidence is accumulating that substantial spatial differences in microclimate across the island are associated with elevational/soil depth change and spatial position at both the island-wide and local scales (Boelhouwers et al. 2003; Hugo et al. 2004; McGeoch et al. 2008; Nyakatya and McGeoch 2008). The acclimatization conditions resulting from local geographic variation in climatic regimes across Marion Island therefore provide a natural framework allowing investigation of evolutionary physiological responses to climate variation. Of particular interest here are differences related to current environmen- tal factors and those resulting from large-scale variation in environmental conditions over longer timescales (e.g. as caused by volcanism, glaciation).

In this study, we focus on the springtail Cryptopygus antarcticus travei Déharveng, 1981 (Collembola, Isotomidae) to examine the extent of spatial metabolic rate variation in a sub-Antarctic ectotherm. This subspecies of the widely distributed nominate species $C$. antarcticus is endemic to Marion Island, a geologically young (<1 Ma; McDougall et al. 2001) island subjected over its short history to subdivision by major cycles of glaciation and periods of substantial volcanic activity (see Myburgh et al. 2007 and references therein). This has resulted in genetic differentiation of populations of indigenous terrestrial arthropods, including C. a. travei (Mortimer and Jansen van Vuuren 2006; Myburgh et al. 2007), which appears to have been an early coloniser in the island's history (Stevens et al. 2006).

Specifically, we investigated whether the long-term persistence of C. a. travei on Marion Island, as well as allowing clear genetic differentiation of geographically discrete populations (see Myburgh et al. 2007), has also led to differentiation of metabolic rates in response to different environmental regimes across the island. We did this by adding significantly to the molecular dataset currently available for $C$. a. travei to further examine genetic characteristics among the Marion Island populations. In conjunction with this work, we obtained complementary data on metabolic rates (measured at constant temperature) for a subset of individuals from six populations in order to examine metabolic rate structuring among populations. Using this combined genetic and physiological dataset, we tested whether spatial structure in metabolic rates was related to genetic structure and systematic environmental variation.

\section{Materials and methods}

Location and sample collection

Marion Island $\left(46^{\circ} 54^{\prime} \mathrm{S}, 37^{\circ} 55^{\prime} \mathrm{E}\right)$ and Prince Edward Island form an isolated archipelago in the Indian Ocean sector of the Southern Ocean (Fig. 1). The climate of the archipelago is cool, wet and windy, with limited seasonal temperature variation and high annual precipitation (Chown and Froneman 2008). Thus, low and high temperatures (in the context of local ranges of variability) can occur at any stage of the year, and warm periods in winter and/or cold periods in summer are common (Deere and Chown 2006). Given its oceanic location, the interplay between stability and unpredictability in terms of temperature variation is likely to have been a feature throughout the history of Marion Island (see Boelhouwers et al. 2008). 
Fig. 1 Map showing the geographic locations on Marion Island referred to in the text. Marion Island's location in the Indian Ocean (inset)

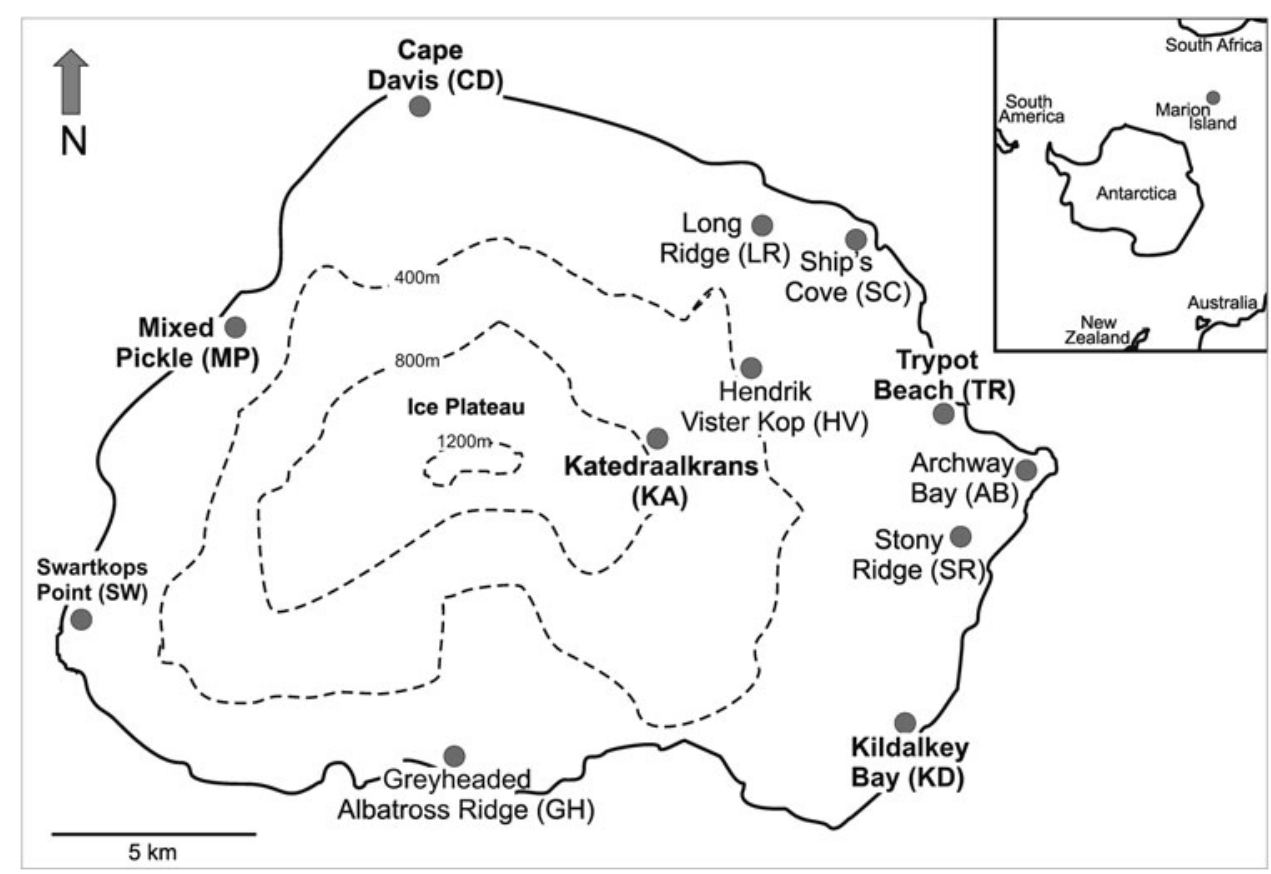

C. a. travei is found across the island, often associated with mosses and the alga Prasiola crispa Menegh. Lightf. Collections of adult animals (and subsequent analyses) were made from six geographic regions [Trypot Beach (TR), Cape Davis (CD), Katedraalkrans (KA), Swartkop Point (SW), Kildalkey Bay (KD), and Mixed Pickle (MP)] (Fig. 1; Online Resource 1) on Marion Island between 14 April and 5 May 2007. After collection, samples were kept outside the laboratory for a minimum of 1 day and a maximum of 3 days in order to maintain near-natural field conditions. Individuals were then moved to plastic vials containing a moist Plaster-of-Paris base and moss shoots as a food source (the moss habitat also includes epiphytic algae, likely to be the primary diet of this species, cf. Worland and Lukesova 2001), and stored at $10 \pm 0.5^{\circ} \mathrm{C}$ in a Sanyo MIR incubator (Sanyo E\&E Europe, Loughborough, UK) (12:12 L:D) for $24 \mathrm{~h}$ prior to metabolic rate measurement.

Population metabolic rate structure

The method employed to measure rates of oxygen consumption followed that of McGaughran et al. (2009). In brief, a fibre-optic oxygen sensing system (Ocean Optics Inc., USA) was used to monitor oxygen partial pressure $\left(p \mathrm{O}_{2}\right)$ over time for individual animals in a closed respirometry system calibrated (by the manufacturer) for multiple temperatures and oxygen percentages. Before each rate measurement was made, a single point calibration in air (20.95 vol\% oxygen) was completed as per the manufacturer's instructions.
Following calibration, individual animals $(n=51)$ that had been starved for $24 \mathrm{~h}$ were placed in a custom-made $40 \mu \mathrm{l}$ chamber (see McGaughran et al. 2009), into which the oxygen probe was inserted. During a 3-h period, temperature and $\mathrm{pO}_{2}$ in the chamber were recorded continuously using oxygen sensing software (OOISensor ver. 1.05, OceanOptics Inc., USA). Temperature during runs was held at $10 \pm 0.1^{\circ} \mathrm{C}$ using a Sable Systems PTC-1 cabinet (Sable Systems, Las Vegas, USA). This measurement temperature was slightly higher than the average summer microhabitat temperature later measured at Marion Island (see "Results"). However, this temperature was selected primarily for comparability to existing metabolic rate work on springtails in continental Antarctica (e.g. McGaughran et al. 2009). Partial pressure profiles were used to calculate oxygen consumption rates on a per animal basis for each individual using the observed drop in $p \mathrm{O}_{2}$ over a given time period in conjunction with chamber volume and gas density calculations using the ideal gas law. An estimate of individual animal mass was used to express corresponding oxygen consumption rates on a mass-specific basis. Photographs of individual springtails were measured using image analysis software (Leica Application Suite, Leica Microsystems, South Africa) and mass was estimated using the relationship: $W=6.1894 L^{3.119} \times 10^{-9}$ (after Block and Tilbrook $1975)$, where $W$ is the mass $(\mu \mathrm{g}), L$ is the length $(\mu \mathrm{m})$, as modelled for $C$. antarcticus antarcticus on maritime Antarctic Signy Island.

While measurements of activity were not possible, all metabolic runs showed constant rates of oxygen percentage decrease over time, therefore we consider that the measure- 
ments obtained are a reasonable estimate of standard metabolic rate. Given the small size of the animals in this study, respiration rates were expected to be near the resolution limit of the oxygen sensing system (see http:// www.oceanoptics.com). Hence, blank runs $(n=10)$ were completed following the protocol above except without the addition of an animal to the measurement chamber, and a mean baseline was calculated and subtracted from each metabolic rate measurement.

\section{Population genetic structure}

Following metabolic rate analysis, total DNA was extracted from 51 individuals via a 'salting-out' procedure (Sunnucks and Hales 1996). Upon extraction, a 710-bp fragment of the mitochondrial cytochrome $c$ oxidase subunit I (COI) gene was amplified using the primers, cycling conditions, and purification methods described in McGaughran et al. (2008), and sequenced on a capillary ABI3730 genetic analyser (Applied Biosystems Inc., Foster City, CA) at the Allan Wilson Centre Genome Service, Massey University. In addition to the 51 sequences obtained in this manner, a further 62 sequences incorporating six extra populations [Ship's Cove (SC), Hendrik Vister Kop (HV), Long Ridge (LR), Archway Bay (AB), Greyheaded Albatross Ridge (GH), Stony Ridge (SR); Fig. 1] from Myburgh et al. (2007) were used to estimate a haplotype network in the programme TCS (ver. 1.21; Clement et al. 2000) using a connection limit of 95\%. An additional haplotype network including only individuals for which metabolic rates were obtained was also generated. Individual metabolic rates were mapped onto this second network to examine the relationship between the partitioning of metabolic rate and molecular genetic structure among populations of $C$. $a$. tra$v e i$. In both networks, missing data in the alignment (which can distort networks; Joly et al. 2007) were not included, and loops were resolved using the criteria suggested by Crandall and Templeton (1993).

The programme ARLEQUIN (ver. 2.000; Schneider et al. 2000) was used to explore genetic characteristics of the distinct populations. Specifically, we obtained measures of haplotype $(h)$ and nucleotide $(\pi)$ diversity indices (Nei 1987) separately for each population, and pairwise differentiation ( $\varphi$-st values) between populations using simple $p$-distances.

\section{Microclimate measurements}

To determine whether the microclimate differed among locations, an iButton thermochron data logger (DS1921; Maxim Integrated Products, Sunnyvale CA, USA) was used to monitor environmental temperature $\left( \pm 0.5^{\circ} \mathrm{C}\right)$ at each of five sites every $60 \mathrm{~min}$ for various periods in 2008 .
These iButtons measure instantaneous temperature at the point of contact between the environment and the thermometer at their base, hence are capable of measuring microhabitat conditions. The iButton was placed just below the soil surface for locations $\mathrm{CD}, \mathrm{MP}, \mathrm{KA}$ and $\mathrm{SW}$ and at $20 \mathrm{~cm}$ below the soil surface for TR. Temperature data were processed to obtain mean daily maximum, minimum, mean and range for each population.

Statistical analyses

Statistical analyses were performed using Minitab (ver. 14; Minitab Inc., Pennsylvania, United States). ANOVA was used to determine if live mass or metabolic rate differed significantly among populations. A Spearman's rank correlation was used to test for any direct relationship between metabolic rate and mean population mass. The same analysis was also used to test for correlation between metabolic rate and mean microclimate measures for each population.

We investigated the relationships among metabolic rate, genetic haplotype and geographic location using univariate tests of significance using a general linear model (GLM). We used metabolic rate as the dependent variable and tested for significance using mass as covariate and location as the categorical factor. This was then repeated using haplotype as the categorical factor. Finally, a GLM analysis was performed where location and haplotype were crossed.

\section{Results}

Population metabolic rate structure

Blank measurement runs generated very low estimates of equipment-generated 'noise', $0.0012 \mu \mathrm{l} \mathrm{O}_{2} \mathrm{~h}^{-1}$ or 0.0001 $\mu \mathrm{O}_{2} \mu \mathrm{g}^{-1} \mathrm{~h}^{-1}$ using the mean live mass of $17.7 \mu \mathrm{g}$. This was much lower than, and significantly different from rates obtained during runs using individual live animals [mean of all data $=0.0019 \pm 0.0002 \mu \mathrm{O} \mathrm{O}_{2} \mu \mathrm{g}^{-1} \mathrm{~h}^{-1}$ (SEM) $\left.(n=51)\right]$ $\left(t_{52}=18.71 ; P<0.001\right)$. Hence, the equipment resolution was sufficient to allow measurement of true rates of metabolism for the size of animals in this study.

Live mass estimates differed significantly between the six populations $\left(F_{5,43}=3.35, P=0.012\right)$, with the TR population showing the highest mean mass $[26.1 \pm 4.6 \mu \mathrm{g}$ (SEM)], followed by $\mathrm{SW}>\mathrm{KD}>\mathrm{CD}>\mathrm{KA}>\mathrm{MP}$ (Table 1 ).

Comparison of metabolic rates also revealed significant differences between these populations $\left(F_{5,43}=3.00\right.$, $P=0.021)$. The $\mathrm{SW}$ population showed the highest mean metabolic rate $\left[0.0029 \pm 0.005 \mu \mathrm{O}_{2} \mu \mathrm{g}^{-1} \mathrm{~h}^{-1}\right.$ (SEM)], followed by: MP $>\mathrm{CD}>\mathrm{KD}>\mathrm{KA}>\mathrm{TR}$ (Fig. 2; Table 1). 
Table 1 Mean live mass $(\mu \mathrm{g}) \pm$ SEM and metabolic rate $\left(\mu \mathrm{O}_{2} \mu \mathrm{g}^{-1} \mathrm{~h}^{-1}\right) \pm$ SEM (with baseline subtracted) for the six geographic locations on Marion Island, from which Cryptopygus antarcticus travei samples were collected and analysed

\begin{tabular}{lrll}
\hline Location & $n$ & $\begin{array}{l}\text { Mean live } \\
\text { mass }(\mu \mathrm{g})\end{array}$ & $\begin{array}{l}\text { Mean metabolic } \\
\text { rate }\left(\mu \mathrm{O}_{2} \mu \mathrm{g}^{-1} \mathrm{~h}^{-1}\right)\end{array}$ \\
\hline Trypot Beach (TR) & 14 & $26.1(4.6)$ & $0.0009(0.0002)$ \\
Cape Davis (CD) & 9 & $11.2(1.8)$ & $0.0021(0.0003)$ \\
Katedraalkrans (KA) & 9 & $11.1(1.6)$ & $0.0014(0.0005)$ \\
Swartkop Point (SW) & 11 & $22.6(3.3)$ & $0.0029(0.0005)$ \\
Kildalkey Bay (KD) & 4 & $14.4(3.8)$ & $0.0016(0.0007)$ \\
Mixed Pickle (MP) & 4 & $8.2(2.6)$ & $0.0024(0.0011)$ \\
\hline
\end{tabular}

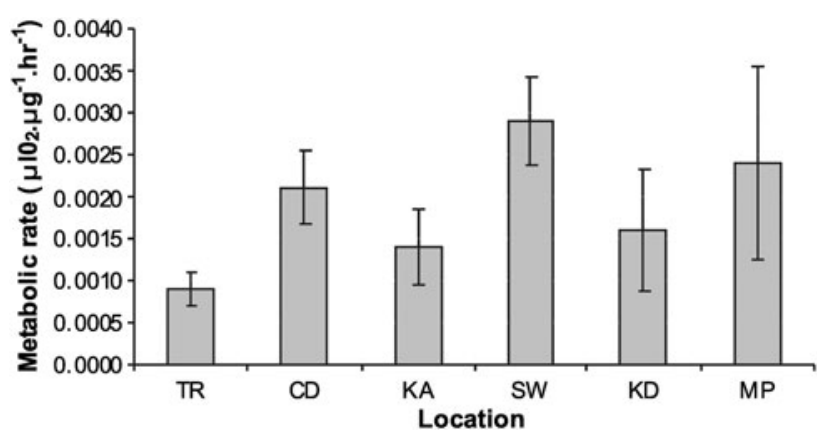

Fig. 2 Mean metabolic rate ( \pm SEM) of Cryptopygus antarcticus travei from six populations (TR Trypot Beach, $C D$ Cape Davis, $K A$ Katedraalkrans, $S W$ Swartkop Point, $K D$ Kildalkey Bay, $M P$ Mixed Pickle) across sub-Antarctic Marion Island

Thus, the population differences in mass do not appear to be reflected in the metabolic rate measurements. This was confirmed by the GLM analyses, which revealed that metabolic rates of the SW population were significantly different from the other populations $\left(F_{5,42}=8.196 ; P<0.001\right)$, with mass non-significant $\left(F_{5,42}=0.531 ; P=0.470\right)$. The Spearman's correlation analysis showed that the differences in metabolic rates among populations were not correlated to mass differences $(r=-0.257 ; P=0.623$ )

Population genetic structure

The network displayed in Fig. 3 shows relationships among the 39 unique haplotypes (30 singletons), obtained from the complete data-set (469 bp; GenBank Accession nos: GQ848918:GQ848956) of 113 sequences of $C$. a. travei. A single haplotype (H1, found in 53 individuals) dominates the network, with the majority of specimens connected by one to three steps to this haplotype. We putatively assign potential "ancestral" status to this haplotype. A single path in the lower half of the network connects a more "derived" set of haplotypes that are separated from the core by a greater number of mutational steps (Fig. 3). Overall, the

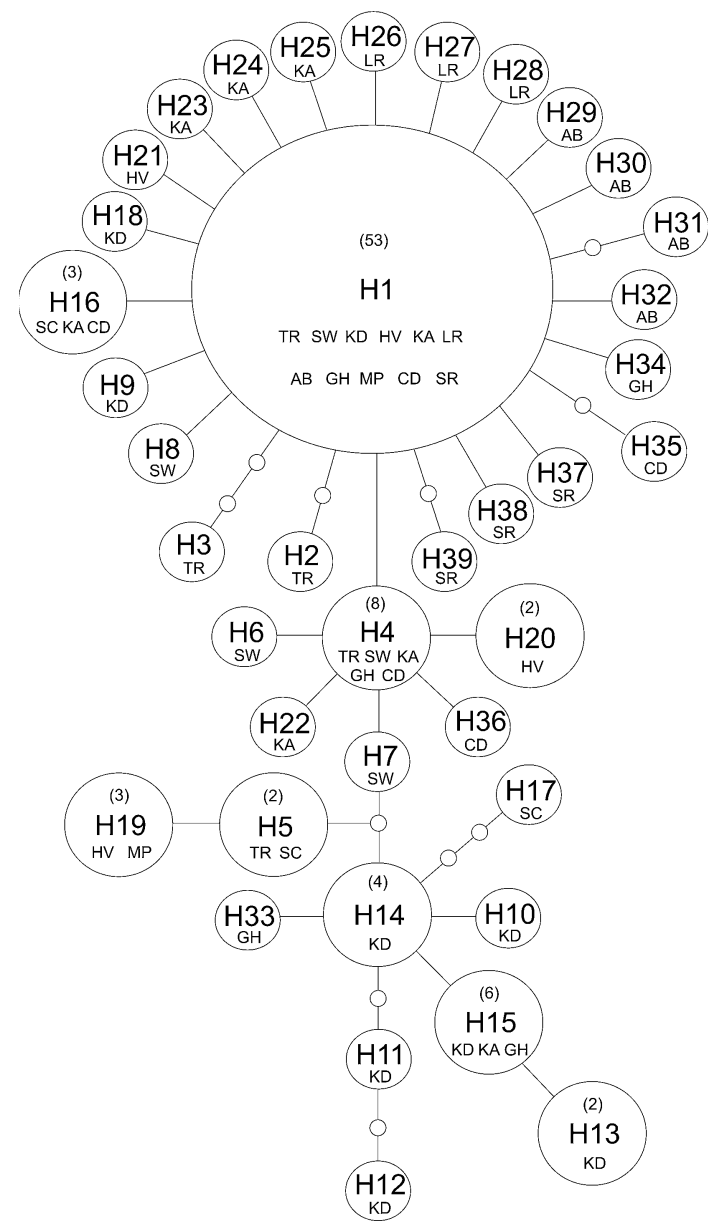

Fig. 3 Haplotype network showing the nucleotide substitution relationships among 39 haplotypes (113 individuals) of Cryptopygus antarcticus travei from Marion Island. For each haplotype, the central label is the haplotype code, the upper value in parentheses is the haplotype frequency (when $>1$ ), and lower label is the population code (see text and Online Resource 1). Each line represents one mutational step, while open circle indicates an inferred or missing haplotype

configuration of this network conforms closely to that of the 610 bp network presented in Myburgh et al. (2007).

Haplotype-sharing among $C$. a. travei populations was common, with 39 haplotypes shared among 113 individuals and six (or 15\%) of the total haplotypes present in more than one population/location. The most common haplotype (H1) was present in all populations except SC (for which $N=3$ ), while the number of haplotypes present in each population was relatively high (e.g. eight haplotypes were present in both the KD and KA populations). Unique haplotypes were present in all populations except MP $(N=4)$, and, in particular, six unique haplotypes were present in the KD population (Table 2). Of all populations, KA showed the greatest number of relationships to other populations with four of its eight haplotypes shared with other populations. 
Table 2 Population statistics and genetic characteristics of sampled locations for Cryptopygus antarcticus travei ( $n$ number of individuals, $h$ haplotype diversity, $\pi$ nucleotide diversity; all statistics calculated in Arlequin ver. 2.000; Schneider et al. 2000)

\begin{tabular}{lclllll}
\hline $\begin{array}{l}\text { Genetic } \\
\text { population }\end{array}$ & $n$ & $\begin{array}{l}\text { No. of } \\
\text { haplotypes }\end{array}$ & $\begin{array}{l}\text { No. of } \\
\text { polymorphic sites }\end{array}$ & $h(\mathrm{SD})$ & $\pi(\mathrm{SD})$ & $\begin{array}{l}\text { Distribution of haplotypes } \\
\text { within populations }\end{array}$ \\
\hline TR & 15 & 5 & 9 & $0.562(0.143)$ & $0.003(0.002)$ & $\mathrm{H} 1, \mathrm{H} 2, \mathrm{H} 3, \mathrm{H} 4, \mathrm{H} 5$ \\
$\mathrm{SW}$ & 20 & 5 & 3 & $0.505(0.126)$ & $0.001(0.001)$ & $\mathrm{H} 1, \mathrm{H} 4, \mathrm{H} 6, \mathrm{H} 7, \mathrm{H} 8$ \\
$\mathrm{KD}$ & 15 & 8 & 10 & $0.895(0.053)$ & $0.006(0.004)$ & $\mathrm{H} 1, \mathrm{H} 9, \mathrm{H} 10, \mathrm{H} 11, \mathrm{H} 12, \mathrm{H} 13, \mathrm{H} 14, \mathrm{H} 15$ \\
$\mathrm{SC}$ & 3 & 3 & 7 & $1.000(0.272)$ & $0.009(0.008)$ & $\mathrm{H} 5, \mathrm{H} 16, \mathrm{H} 17$ \\
$\mathrm{HV}$ & 9 & 5 & 8 & $0.861(0.087)$ & $0.006(0.004)$ & $\mathrm{H} 1, \mathrm{H} 18, \mathrm{H} 19, \mathrm{H} 20, \mathrm{H} 21$ \\
$\mathrm{KA}$ & 13 & 8 & 9 & $0.808(0.113)$ & $0.004(0.002)$ & $\mathrm{H} 1, \mathrm{H} 4, \mathrm{H} 15, \mathrm{H} 16, \mathrm{H} 22, \mathrm{H} 23, \mathrm{H} 24, \mathrm{H} 25$ \\
$\mathrm{LR}$ & 4 & 4 & 3 & $1.000(0.177)$ & $0.003(0.003)$ & $\mathrm{H} 1, \mathrm{H} 26, \mathrm{H} 27, \mathrm{H} 28$ \\
$\mathrm{AB}$ & 6 & 5 & 5 & $0.933(0.122)$ & $0.004(0.003)$ & $\mathrm{H} 1, \mathrm{H} 29, \mathrm{H} 30, \mathrm{H} 31, \mathrm{H} 32$ \\
$\mathrm{GH}$ & 7 & 5 & 7 & $0.905(0.103)$ & $0.007(0.004)$ & $\mathrm{H} 1, \mathrm{H} 4, \mathrm{H} 15, \mathrm{H} 33, \mathrm{H} 34$ \\
MP & 4 & 2 & 5 & $0.500(0.265)$ & $0.005(0.004)$ & $\mathrm{H} 1, \mathrm{H} 19$ \\
$\mathrm{CD}$ & 11 & 5 & 5 & $0.618(0.164)$ & $0.002(0.002)$ & $\mathrm{H} 1, \mathrm{H} 4, \mathrm{H} 16, \mathrm{H} 35, \mathrm{H} 36$ \\
SR & 6 & 4 & 4 & $0.800(0.172)$ & $0.003(0.002)$ & $\mathrm{H} 1, \mathrm{H} 37, \mathrm{H} 38, \mathrm{H} 39$ \\
\hline
\end{tabular}

Genetic population codes correspond to those used in Online Resource 1

Haplotype diversity ( $h$ ) for $C$. a. travei (excluding locations where $N<4$ ) ranged from 0.505 to 0.933 and was highest $(h=0.933 \pm 0.122)$ in the $\mathrm{AB}$ population (Table 2). Measures of nucleotide diversity $(\pi)$ were highest in the $\mathrm{GH}$ population $(\pi=0.007 \pm 0.004)$. Several $\varphi$-st values were large and significant; a general indication of long-term isolation and low gene flow between locations (Table 3). The similarity of KA to other populations (see above) was indicated by comparatively low $\varphi$-st values (ranging from 0.006 to 0.417 between KA and other populations; Table 3).

Metabolic rate and genetic structure

The relationship between patterns of metabolic rate and genetic structure is illustrated in Fig. 4, which shows the subset of individuals for which a metabolic rate and genetic measurement was made. To produce this figure, metabolic rate data were grouped arbitrarily into three roughly equal-sized categories corresponding to 'low' $\left(<0.0010 \mu \mathrm{l} \mathrm{O}_{2} \mu \mathrm{g}^{-1} \mathrm{~h}^{-1}\right)$, 'medium' $\left(0.0010<x<0.0020 \mu \mathrm{O}_{2} \mu \mathrm{g}^{-1} \mathrm{~h}^{-1}\right)$, and 'high' (>0.0020 $\mu \mathrm{l} \mathrm{O}_{2} \mu \mathrm{g}^{-1} \mathrm{~h}^{-1}$ ). This metabolic rate classification was then mapped (via shading) onto the (reduced) haplotype network to give a graphical representation of any relationship between mutation rate and metabolic rate.

While individuals with the central haplotype $(\mathrm{H} 1)$ represent all populations and all metabolic rate ranks, several of the haplotypes from individuals with high and medium metabolic ranks were more "derived" genetically [i.e. they are one or more mutational $\operatorname{step}(\mathrm{s})$ away from the central haplotype]. Conversely, individuals with a low metabolic rank have haplotype designations that include the central

Table 3 Pairwise population $\varphi$-st values based on 469 bp of COI for 113 Cryptopygus antarcticus travei specimens

\begin{tabular}{|c|c|c|c|c|c|c|c|c|c|c|c|c|}
\hline Population & TR & SW & $\mathrm{KD}$ & $\mathrm{SC}$ & HV & KA & LR & $\mathrm{AB}$ & $\mathrm{GH}$ & MP & $\mathrm{CD}$ & SR \\
\hline Trypot Beach (TR) & 0.132 & & & & & & & & & & & \\
\hline Swartkop Point (SW) & 0.021 & 0.194 & & & & & & & & & & \\
\hline Kildalkey Bay (KD) & 0.488 & 0.559 & 0.374 & & & & & & & & & \\
\hline Ship's Cove (SC) & 0.472 & 0.635 & 0.100 & 0.330 & & & & & & & & \\
\hline Hendrik Vister Kop (HV) & 0.050 & 0.111 & 0.278 & 0.144 & 0.103 & & & & & & & \\
\hline Katedraalkrans (KA) & 0.027 & 0.006 & 0.417 & 0.385 & 0.016 & 0.108 & & & & & & \\
\hline Long Ridge (LR) & 0.026 & 0.153 & 0.473 & 0.397 & 0.071 & 0.017 & 0.128 & & & & & \\
\hline Archway Bay (AB) & 0.072 & 0.174 & 0.491 & 0.429 & 0.118 & 0.065 & 0.028 & 0.162 & & & & \\
\hline Greyheaded Albatross Ridge (GH) & 0.206 & 0.304 & 0.065 & 0.013 & 0.012 & 0.116 & 0.193 & 0.233 & 0.154 & & & \\
\hline Mixed Pickle (MP) & 0.043 & 0.072 & 0.251 & 0.076 & 0.163 & 0.085 & 0.000 & 0.044 & 0.090 & 0.078 & & \\
\hline Cape Davis (CD) & 0.035 & 0.009 & 0.497 & 0.512 & 0.070 & 0.034 & 0.046 & 0.082 & 0.226 & 0.004 & 0.140 & \\
\hline Stony Ridge (SR) & 0.017 & 0.090 & 0.495 & 0.465 & 0.100 & 0.019 & 0.006 & 0.040 & 0.233 & 0.030 & 0.025 & 0.138 \\
\hline
\end{tabular}

Numbers in italics denote comparisons for which $P<0.05$; average pairwise differences within localities are indicated in the diagonal 


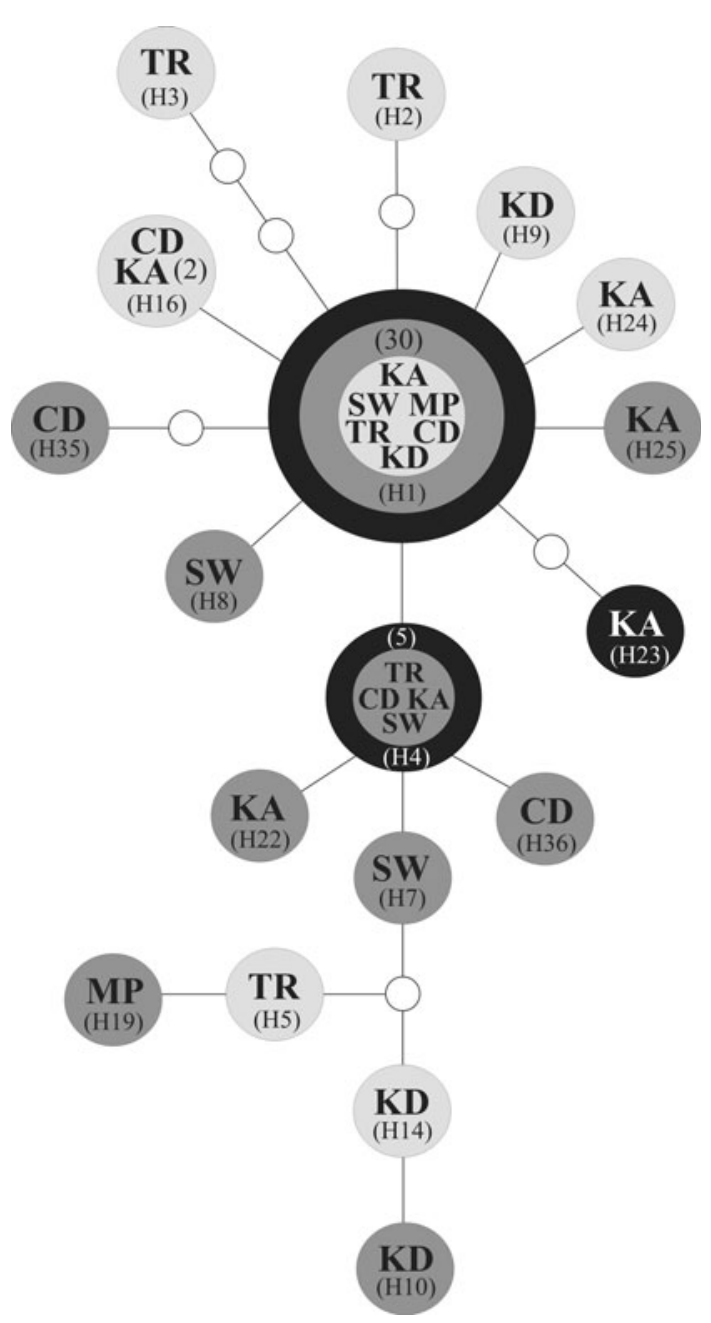

Fig. 4 A haplotype network showing only those individuals for which a metabolic rate is known. The shading indicates whether individuals with that haplotype have low $\left(<0.0010 \mu \mathrm{l} \mathrm{O}_{2} \mu \mathrm{g}^{-1} \mathrm{~h}^{-1}\right.$; light grey $)$, medium $\left(0.0010<x<0.0050 \mu \mathrm{O}_{2} \mu \mathrm{g}^{-1} \mathrm{~h}^{-1}\right.$; darker grey) or high $\left(>0.0050 \mu \mathrm{l} \mathrm{O}_{2} \mu \mathrm{g}^{-1} \mathrm{~h}^{-1}\right.$; black) metabolic rates. Labels within haplotypes refer to population codes (see text and Online Resource 1) and numbers in parentheses indicate haplotype frequency (when $>1$ )

(putatively "ancestral") haplotype 'H1', and several haplotypes that are within 1-3 mutational steps from this haplotype. The only exception to this pattern involves two haplotypes that represent individuals with 'low' metabolic ranks (H5 and H14) in the lower part of the network. Thus, our interpretation of Fig. 4 is that it provides weak support for an overall similarity between population genetic and metabolic rate structure among populations.

The GLM analyses did not provide statistical support for this potential pattern; when haplotype was used as the categorical factor, both haplotype $\left(F_{2,45}=0.619 ; P=0.543\right)$ and mass $\left(F_{2,45}=1.942 ; P=0.170\right)$ were non-significant. Additionally, the GLM analysis where location and haplotype were crossed gave a non-significant result $\left(F_{4,36}=0.619 ; P=0.652\right)$.
Table 4 Microclimate temperature parameters $\left({ }^{\circ} \mathrm{C}\right)$, including mean, maximum, minimum, and range for five geographic locations on Marion Island 2008 for various periods throughout 01 April to 14 May 2008

\begin{tabular}{llllll}
\hline Location & $\begin{array}{l}\text { Period of data } \\
\text { collection }\end{array}$ & Mean & Maximum & Minimum & Range \\
\hline $\mathrm{TR}^{\mathrm{a}}$ & $06.04 .08-18.04 .08$ & 6.9 & 7.7 & 6.3 & 1.4 \\
$\mathrm{SW}$ & $14.04 .08-14.05 .08$ & 5.0 & 9.3 & 2.0 & 7.1 \\
$\mathrm{KA}$ & $01.04 .08-15.04 .08$ & 2.0 & 3.2 & 1.1 & 2.0 \\
$\mathrm{MP}$ & $12.04 .08-12.05 .08$ & 5.2 & 9.3 & 2.2 & 7.1 \\
$\mathrm{CD}$ & $12.04 .08-12.05 .08$ & 5.0 & 8.0 & 2.3 & 5.8
\end{tabular}

TR Trypot Beach, $S W$ Swartkop Point, KA Katedraalkrans, MP Mixed Pickle, $C D$ Cape Davis

${ }^{a}$ NB: these data were collected at $20 \mathrm{~cm}$ below the soil surface; all other data were collected from just beneath the soil surface

\section{Microclimate measurements}

The microclimate data showed that the CD, SW and MP populations were all relatively similar in their temperature mean, maxima, minima and range profiles. However, differences between these populations and KA and TR were apparent (Table 4). The high-altitude site (KA) had lower temperatures than the other (low altitude) coastal sites and had a lower range of temperature variability. The TR population had the highest mean and minimum temperature of all sites and also the lowest range. However, the TR data were collected $20 \mathrm{~cm}$ below the soil surface and this probably accounts for the lower range of variability at this site. The TR data are therefore of limited comparative value with the other sites (Table 4).

Metabolic rate and microclimate

The Spearman's rank correlation analysis showed a strongly significant relationship between mean metabolic rate and temperature range $(r=0.972 ; P=0.006)$. However, the Spearman's correlations with mean and minimum temperature were non-significant $[r=-0.107(P=0.865)$ and $r=-0.400(P=0.505)$, respectively].

\section{Discussion}

Local and regional environmental variability have been found to underlie spatial variation of a range of (non-metabolic) factors that are significant in determining organism life histories and wider-scale biological distributions. For example, current patterns of biodiversity across the Antarctic continent are thought to be a response to geographic variation in environmental conditions over time (Peck et al. 
2006). Investment in reproduction is greater in northern (sub-Antarctic) populations of the mite Alaskozetes antarcticus than in southern (maritime Antarctic) populations (Convey 1998) and, in plants, the balance between sexual or asexual modes of reproduction and dispersal changes with progression into more extreme environmental conditions (Convey 1996a, c; Adams et al. 2006).

Such spatial assortment corresponding to the landscape may also be prevalent at fine scales and indeed, the work of Hawes et al. (2008b) showed the extent to which a few centimetres of moss, let alone different habitats on a relatively large island, may lead to physiological variation. In the current study, metabolic rates of $C$. a. travei were found to vary significantly among discrete populations on Marion Island despite our relatively small sample size. In particular, populations from the western side of the island (SW, MP and CD) had higher mean metabolic rates than populations located centrally (KA) or on the eastern side of the island (KD and TR) (Fig. 4). A north/east-south/ west divide in population genetic structure, and the importance of central grey lava outcrops as refugia, have been proposed for arthropod species on the island (Mortimer and Jansen van Vuuren 2006; Myburgh et al. 2007), and may also be influential factors in the current study. However, while metabolic rate variation among populations was apparent, its expression was relatively inconsistent. Our analyses indicated that neither genetic haplotype, nor location were responsible for the patterns of metabolic rate structure. However, two important external findings suggest that closer examination of both microclimate and genetic data may yield further information about any spatial structuring among populations, especially for cases with larger sample sizes. First, an east-west signal in temperature mean and range has been detected across Marion Island (Nyakatya and McGeoch 2008), and second, historical and population genetic evidence exists for a substantial north/east-south/west geological divide (Mortimer and Jansen van Vuuren 2006; Myburgh et al. 2007; Boelhouwers et al. 2008).

Contemporary climate conditions have been described along an altitudinal gradient for Marion Island, where the mean annual temperature experienced by invertebrate fauna was approximately $6^{\circ} \mathrm{C}$ in lowland areas of the island, and $3^{\circ} \mathrm{C}$ at $750 \mathrm{~m}$ a.s.l. (Chown et al. 1997). Investigating the consequences of this temperature gradient for biota, Chown et al. (1997) found that metabolic rates of weevil species (Coleoptera) were generally greater in high-altitude populations, providing an example of MCA. A further study focusing on thermotolerance variation in Marion Island weevil species found significant intraspecific thermotolerance differences across a climatic gradient (Klok and Chown 2003). The present study suggests that in addition to such altitudinally-related variation, other forms of spatial variation in physiological variables might also exist and should be investigated.

In general, temperature clearly impacts all physiological and biochemical processes, and thus plays a central role within a large component of animal life histories (Nespolo et al. 2003). However, as other environmental variables can interact and/or covary with temperature, it is often difficult to separate the causal effects of temperature alone (AddoBediako et al. 2002). Nevertheless, mass-specific metabolic rates obtained in the current study account for body size [the primary determinant of resting metabolic rate in interspecific comparisons among invertebrates alongside temperature (Gillooly et al. 2001; Makarieva et al. 2005)], and individual mass, while different among populations, did not explain metabolic rate differences despite the known affects of body mass on metabolic rate (e.g. Block and Tilbrook 1975; Block and Young 1978). Thus, a strong contender for a contemporary determinant of the patterns observed in this study is likely to be ambient temperature variation across microhabitats in the different regions of Marion Island.

While the microclimate data obtained in the current study contained only a small amount of overlap between populations and was able to be drawn from just a single replicate per site, it did provide an indication that the temperature of springtail habitats differs among locations on Marion Island (see Table 4). In particular, KA was subject to much lower temperatures and a lower range of variability than the other locations, which is not surprising given its high altitude (768 $\mathrm{m}$ a.s.1.). It is interesting that KA differed in temperature profile from the other locations and also had one of the lowest mean metabolic rates. It is possible that for this site, low temperatures at high altitude place a restriction on organism activity. Conversely, the SW, MP and CD populations all had similar (high) temperature mean and maxima, and a comparatively high degree of variability (i.e. a high temperature range), and these populations had the highest metabolic rates in this study. The Spearman's correlation analysis found support for a strong relationship between mean metabolic rate and microclimate temperature range. Thus, the higher variability of these coastal sites may have resulted in an enhanced ability of these populations to take advantage of higher temperatures when they occur. Further investigation of the potential role of plasticity of organism response to habitat variability on Marion Island would be useful in this regard.

In addition to the demonstrated importance of the modern microclimate, historical environmental factors are likely to have played a role in directing population structure (Avise 2000) on Marion Island. Clear genetic differentiation of populations at fine scales appears to be a feature of Antarctic systems (e.g. Stevens et al. 2007; McGaughran et al. 2008) that extends to the sub-Antarctic environment (e.g. Mortimer and Jansen van Vuuren 2006; Myburgh 
et al. 2007). In particular, the combined effects of periodic volcanism on Marion Island and of Pleistocene glaciation have driven a pattern of inter-population divergence for several terrestrial arthropods (Mortimer and Jansen van Vuuren 2006; Myburgh et al. 2007).

The data obtained in the current study provide further support for the genetic substructuring of populations of $C$. a. travei. Of the 12 populations studied, unique haplotypes were present in 11 populations (all except MP, but the sample size for this population was low) - a pattern consistent with divergence in isolation. Conversely, high haplotype sharing among the 113 individuals, in addition to specific genetic relationships shown at the population level (e.g. KA shared four haplotypes with other populations; GH, TR and $\mathrm{CD}$ each shared three haplotypes with other populations) suggests the presence of a 'global pool' of genetic diversity, from which extant populations are likely sourced. The star-like structure of the network presented in Fig. 3 indicates a population expansion in the recent genetic history of C. a. travei (see Slatkin and Hudson 1991), and a high-altitude refugial population (e.g. a nunatak) such as could have been provided by KA, may have played a role in this.

The mean metabolic rate structure among populations showed a pattern of: $\mathrm{SW}>\mathrm{MP}>\mathrm{CD}>\mathrm{KD}>\mathrm{KA}>\mathrm{TR}$. Although TR and KA populations had the lowest mean metabolic rates, individual members of these populations also had 'high' and 'medium' metabolic rates. When examined in concert with the haplotype distribution, the KD population is very distinct from the other populations (with six unique haplotypes), but still shares two haplotypes (H1 and H15) with KA. The remaining populations for which metabolic rate data exist also share haplotypes (e.g. H1 and H4) with KA. Thus, it is possible that the KA population represents a refugial source population from which current populations have spread and become structured (both genetically and physiologically).

The collective results of this study suggest that the conditions that have driven molecular structuring of populations of $C$. a. travei may also have resulted in some degree of differentiation in physiological parameters between populations over time. In addition, differences between populations are likely to reflect (largely temperature) variation in different microhabitats across the island. We suggest that response to both historical factors and contemporary environmental variability have likely played a significant role in defining physiological and genetic structure among populations of $C$. a. travei on Marion Island. Further development of this hypothesis requires comparative studies on larger datasets from Marion Island and beyond, to enable a greater understanding of the roles contemporary and historical environments play in shaping population parameters and potentially determining plasticity of organism responses to habitat variability.
Acknowledgments We thank T. Hawes and two anonymous reviewers for constructive comments on an earlier version of the manuscript. We thank members of the Centre for Invasion Biology, University of Stellenbosch, and colleagues on Marion Island, particularly Valdon Smith, Charlene Scheepers and Elrike Marais. AM was supported by a New Zealand Tertiary Education Commission Top Achievers Doctoral Scholarship. This paper forms a contribution to the SCAR EBA research programme.

\section{References}

Adams BJ, Bardgett RD, Ayres E, Wall DH, Aislabie J, Bamforth S, Bargagli R, Cary C, Cavacini P, Connell L, Convey P, Fell JW, Frati F, Hogg ID, Newsham KK, O’Donnell A, Russell N, Seppelt RD, Stevens MI (2006) Diversity and distribution of Victoria Land biota. Soil Biol Biochem 38:3003-3018

Addo-Bediako A, Chown SL, Gaston KJ (2002) Metabolic cold adaptation in insects: a large scale perspective. Funct Ecol 16:332-338

Avise JC (2000) Phylogeography: the history and formation of species. Harvard University Press, USA

Block W (1990) Cold tolerance of insects and other arthropods. Philos Trans Roy Soc B 326:613-633

Block W, Tilbrook PJ (1975) Respiration studies on the Antarctic collembolan Cryptopygus antarcticus. Oikos 26:15-25

Block W, Young SR (1978) Metabolic adaptations of Antarctic terrestrial micro-arthropods. Comp Biochem Phys A 61:363-368

Boelhouwers JC, Holness S, Sumner P (2003) The maritime sub-Antarctic: a distinct periglacial environment. Geomorphology 52:39-55

Boelhouwers JC, Meiklejohn KI, Holness SD, Hedding DW (2008) Geology, geomorphology and climate change. In: Chown SL, Froneman PW (eds) The Prince Edward Islands, Land-sea interactions in a changing ecosystem. African Sunmedia, South Africa, pp 65-96

Chown SL (1997) Thermal sensitivity of oxygen uptake of Diptera from sub-Antarctic South Georgia and Marion Island. Polar Biol 17:81-86

Chown SL, Convey P (2007) Spatial and temporal variability across life's hierarchies in the terrestrial Antarctic. Philos Trans Roy Soc B 362:2307-2331

Chown SL, Froneman PW (2008) The Prince Edward Islands. Land, sea interactions in a changing ecosystem. African SunMedia, South Africa

Chown SL, van der Merwe M, Smith VR (1997) The influence of habitat and altitude on oxygen uptake in sub-antarctic weevils. Physiol Zool 70:116-124

Clarke A (1993) Seasonal acclimation and latitudinal compensation in metabolism: do they exist? Funct Ecol 7:139-149

Clarke A (1998) Temperature and energetics: a review of cold ocean physiology. In: Pörtner HO, Playle RC (eds) Cold ocean physiology. Society for Experimental Biology Seminar, Series no. 66, pp 3-30

Clement MD, Posada D, Crandall KA (2000) TCS: a computer program to estimate gene genealogies. Mol Ecol 9:1657-1659

Convey P (1996a) The influence of environmental characteristics on life history attributes of Antarctic terrestrial biota. Biol Rev $71: 191-225$

Convey P (1996b) Overwintering strategies of terrestrial invertebrates in Antarctica-the significance of flexibility in extremely seasonal environments. Eur J Entomol 93:489-505

Convey P (1996c) Reproduction of Antarctic flowering plants. Antarct Sci 8:127-134

Convey P (1998) Latitudinal variation in allocation to reproduction by the Antarctic oribatid mite, Alaskozetes antarcticus. Appl Soil Ecol 9:93-99 
Crandall KA, Templeton AR (1993) Empirical tests of some predictions from coalescent theory. Genetics 134:619-633

Davey MC, Rothery P (1996) Seasonal variation in respiratory and photosynthetic parameters in three mosses from the maritime Antarctic. Ann Bot 78:719-728

Deere JA, Chown SL (2006) Testing the beneficial acclimation hypothesis and its alternatives for locomoter performance. Am Nat 168:630-644

Gillooly JF, Brown JH, West GB, Savage VM, Charnov EL (2001) Effects of size and temperature on metabolic rate. Science 293:2248-2251

Hawes TC, Worland MR, Bale JS, Convey P (2008a) Rafting in Antarctic Collembola. J Zool 274:44-50

Hawes TC, Bale JS, Worland MR, Convey P (2008b) Trade-offs between microhabitat selection and physiological plasticity in the Antarctic springtail, Cryptopygus antarcticus (Willem). Polar Biol 31:68-689

Hugo EA, McGeoch MA, Marshall DJ, Chown SL (2004) Fine scale variation in microarthropod communities inhabiting the keystone species Azorella selago on Marion Island. Polar Biol 27:466-473

Joly S, Stevens MI, Jansen van Vuuren B (2007) Haplotype networks can be misleading in the presence of missing data. Syst Biol $56: 857-862$

Klok CJ, Chown SL (2003) Resistance to temperature extremes in subAntarctic weevils: interspecific variation, population differentiation and acclimation. Biol J Linn Soc 78:401-414

Klok CJ, Chown SL (2005) Inertia in physiological traits: Embyonopsis halticella caterpillars (Yponomeutidae) across the Antarctic Polar Frontal Zone. J Insect Physiol 51:87-97

Kozłowski J, Czarnoleski M, Dańko M (2004) Can optimal resource allocation models explain why ectotherms grow larger in cold? Integr Comp Biol 44:480-493

Lardies MA, Bozinovic F (2008) Genetic variation for plasticity in physiological and life-history traits among populations of an invasive species, the terrestrial isopod Porcellio laevis. Evol Ecol Res 10:747-762

Lardies MA, Catalan TP, Bozinovic F (2004) Metabolism and lifehistory correlates in a lowland and highland population of a terrestrial isopod. Can J Zool 82:677-687

Makarieva AM, Gorshkov VG, Li B-L (2005) Biochemical universality of living matter and its metabolic implications. Funct Ecol 19:547-557

McDougall I, Verwoerd W, Chevallier L (2001) K-Ar geochronology of Marion Island, Southern Ocean. Geol Mag 138:1-17

McGaughran A, Hogg ID, Stevens MI (2008) Patterns of population genetic structure for springtails and mites in southern Victoria Land, Antarctica. Mol Phylogenet Evol 46:606-618

McGaughran A, Redding GP, Stevens MI, Convey P (2009) Temporal metabolic rate variation in a continental Antarctic springtail. J Insect Physiol 55:129-134

McGeoch MA, Le Roux PC, Hugo EA, Nyakatya MJ (2008) Spatial variation in the terrestrial biotic system. In: Chown SL, Froneman PW (eds) The Prince Edward Islands. Land-Sea interactions in a changing ecosystem. African SunMedia, South Africa, pp 245-276

Mitton JB, Carey C, Kocher TD (1986) The relation of enzyme heterozygosity to standard and active oxygen consumption and body size of tiger salamanders, Ambystoma tigrinum. Physiol Zool 59:574-582

Mortimer E, Jansen van Vuuren B (2006) Phylogeography of Eupodes minutus (Acari: Prostigmata) on sub-Antarctic Marion Island reflects the impact of historical events. Polar Biol 30:471-476

Myburgh M, Chown SL, Daniels SR, Jansen van Vuuren B (2007) Population structure, propagule pressure, and conservation biogeography in the sub-Antarctic: lessons from indigenous and invasive springtails. Divers Distrib 13:143-154

Nei M (1987) Molecular evolutionary genetics. Columbia University Press, USA

Nespolo RF, Lardies MA, Bozinovic F (2003) Intrapopulational variation in the standard metabolic rate of insects: repeatability, thermal dependence and sensitivity $\left(\mathrm{Q}_{10}\right)$ of oxygen consumption in a cricket. J Exp Biol 206:4309-4315

Nyakatya MJ, McGeoch MA (2008) Temperature variation across Marion Island associated with a keystone plant species (Azorella selago Hook. (Apiaceae)). Polar Biol 31:139-151

Peck LS, Convey P, Barnes DKA (2006) Environmental constraints on life histories in Antarctic ecosystems: tempos, timings and predictability. Biol Rev 81:75-109

Pujolar JM, Maes GE, Vancoillie C, Volckaert FAM (2005) Growth rate correlates to individual heterozygosity in the European eel, Anguilla anguilla L. Evolution 59:189-199

Schneider S, Roessli D, Excoffier L (2000) Arlequin ver. 2.000: a software for population genetics data analysis. Genetics and Biometry Laboratory, University of Geneva, Switzerland

Sinclair BJ, Addo-Bediako A, Chown SL (2003) Climatic variability and the evolution of insect freeze tolerance. Biol Rev 78:181-195

Slatkin M, Hudson RR (1991) Pairwise comparisons of mitochondrial DNA sequences in stable and exponentially growing populations. Genetics 129:555-562

Sømme L, Ring RA, Block W, Worland MR (1989) Respiratory metabolism of Hydromedion sparsutum and Perimylops antarcticus (Col., Perimylopidae) from South Georgia. Polar Biol 10:135-139

Stevens MI, Greenslade P, Hogg ID, Sunnucks P (2006) Examining Southern Hemisphere springtails: could any have survived glaciation of Antarctica? Mol Biol Evol 23:874-882

Stevens MI, Frati F, McGaughran A, Spinsanti G, Hogg ID (2007) Phylogeographic structure suggests multiple glacial refugia in northern Victoria Land for the endemic Antarctic springtail Desoria klovstadi (Collembola, Isotomidae). Zool Scr 36:201-212

Strømme JA, Ngari TW, Zachariassen KE (1986) Physiological adaptations in Coleoptera on Spitzbergen. Polar Res 4:199-204

Sunnucks P, Hales DF (1996) Numerous transposed sequences of mitochondrial cytochrome oxidase I-II in aphids of the genus Sitobion (Hemiptera: Aphididae). Mol Biol Evol 13:510-524

Teska WR, Smith MH, Novak JM (1990) Food quality, heterozygosity, and fitness correlates in Peromyscus polionotus. Evolution 44:1318-1325

Worland MR, Lukesova A (2001) The application of differential scanning calorimetry and ice nucleation spectrometry to ecophysiological studies of algae. Nova Hedwigia 123:571-583 